\title{
Experimental Investigation of Energy Consumption of A Commercial Walk- in Freezer
}

\author{
Mohamed Metwalli, Minhajul Haque Minar, Mostafa H. Sharqawy* \\ School of Engineering, College of Engineering and Physical Sciences, \\ University of Guelph, Guelph, Ontario N1G 2W1, Canada \\ melsharq@uoguelph.ca
}

\begin{abstract}
Refrigerators and coolers are an essential part of the food industry. They are working based on the vapor compression cycle which requires energy input to absorb heat from the cold space and reject it to the ambient. Alongside this energy, there is energy drainage source coming from the need to melt a frost layer that is accumulated on the cooling coil surface due to its low temperature which is below the freezing point. The energy used in defrosting evaporator coils is a wasted energy that costs a lot especially when it is used in a large-scale units like food storage warehouses. The present paper is exploring and examining the energy required to operate a commercial walk-in freezer. The freezer was tested using two different defrost process controls. The energy consumption data were recorded and analyzed to evaluate the defrost refrigeration ratio (DRR) and perform a cost analysis of one year of operation. The tested unit was operated in two modes, the first is fixed time scheduled defrost and the second is on-demand defrost (adaptive strategy) for comparison. The results show that the defrost-to-refrigeration energy consumption ratio is $2 \%$ and the annual cost of operation is $\$ 438$ when the freezer is operating under on-demand mode. In addition to that, the defrost ratio in scheduled defrost is $29 \%$ and $19 \%$ for defrost initiation every four and six hours, respectively. Moreover, their annual operating cost is $\$ 528$ and $\$ 511$, respectively. Based on that, the reduction in operating costs due to the use of on-demand mode is $21 \%$ and $17 \%$ compared to scheduled defrost every four and six hours.
\end{abstract}

Keywords: Refrigeration, Walk-in Freezer, Defrost Energy, Energy Consumption.

\section{Introduction}

In the food industry, the necessity to store food and beverages brings the need to use devices and machines such as refrigerators and freezers. The working principle of such machines is the vapor compression cycle which provides the required cooling capacity as per the stored loads. In vapor compression cycles, heat is absorbed from the low-temperature cold space and heat is rejected to the high-temperature ambient. To perform such a task, energy input is required to power the compressor, fans, and other assisting components in the cycle. This energy is mostly in the form of electric power that is drawn by a motor to operate a compressor. Another energy drainage source is defrost energy. In freezers and frozen food warehouses, the temperature of the evaporator coil surface is below the freezing point which excites frost deposition on the coil surface. Frost accumulation over time negatively impacts the heat transfer capabilities of the coil which will lead to a drop in the cooling capacity of the freezer. Consequently, periodic defrosting is utilized to maintain the operating conditions as desired.

Defrost mechanisms are variant, and they can be categorized into two groups based on power provision. The first category is passive defrost methods where the surface morphology is altered to reduce frost deposition rate, decrease its density (make it fragile), or prevent its accumulation under certain conditions without the need for outsourced power supply. The second kind is active defrost methods that rely on an external power supply to defrost the frost layer without modifying or changing the surface properties. In almost every machine or device, there is a control system to ensure and maintain the running device in its best condition and performance. Defrost control strategies are various, and they vary and differ between each other based on the criteria used to build the unit. Parameters that play a role in the determination of defrost initiation timing are but not restricted to, pressure drop, evaporator fan power, frost thickness, and evaporator effectiveness. Till now 
there is not any developed definitive set of criteria to create the ultimate adaptive defrost control, although the diligent efforts from many researchers. The common defrost control strategy is based on a scheduled timer due to its simplicity and its familiarity with the refrigeration technicians. Experts recommend adjusting the time to start defrosting every 4 , 6, or 8 hours depending on the size of the cold space and load. This defrost strategy was proven to waste energy and money, despite that, it still remained in usage until the present day [1].

Different models are available to predict the freezers operating energy consumption with an acceptable margin of error. Mastrullo et al. [2] developed a transient model to estimate the cabinet temperature and energy consumption considering air leakage, door openings, and frost formation for a vertical commercial freezer. Borges et al. [3] introduced a model to estimate the energy requirements of household refrigerators without considering frosting conditions. Later on, they improved their model to predict the energy drainage accounting for the frosting conditions and door openings [4]. Another forecasting model was introduced for a commercial freezer unit which did not take into consideration frost accumulation on the evaporator coil [5]. For walk-in freezers, Behfar and Yuill [6] evaluated the consumed energy rate and simulated the performance based on a semi-empirical mathematical model considering frost-free conditions.

The ratio of the energy consumed for defrosting to the energy used for refrigeration is an important performance parameter that shows the potential of energy saving in large commercial walk-in freezers. Little or no data are available in the literature for such a ratio for walk-in freezers. This paper represents an experimental investigation of the walk-in freezer using two defrost control strategies, scheduled (based on time) and on-demand (Adaptive control). In addition, a cost analysis of the refrigeration and defrost energies are presented for a duration of one year.

\section{Experimental Apparatus}

The tested unit is a walk-in freezer of $1.17 \mathrm{~m}$ (width) $\times 1.75 \mathrm{~m}$ (length) $\times 2.40 \mathrm{~m}$ (height). The unit has a $1 \mathrm{hp}$ compressor and an evaporator coil of 1500 Watts cooling capacity at $-18{ }^{\circ} \mathrm{C}$ using R-404A refrigerant. The walk-in freezer is insulated with 3 inches of polyurethane foamed in place. The specifications of the other components are listed in Table 1. In addition, a photograph of the freezer is shown in Figure 1.

Table 1: Walk-in freezer components summery

\begin{tabular}{ll}
\hline Component & Specifications \\
\hline Condensing unit & $1 \mathrm{hp}$ compressor, $208 \mathrm{~V}, 1$ phase, $60 \mathrm{~Hz}$, with an air-cooled condenser and 1 fan \\
Evaporator coil & $1.5 \mathrm{~kW}$ cooling capacity at $-18^{\circ} \mathrm{C} .3 \mathrm{fans}$ of $208 \mathrm{~V}, 1$ phase, $60 \mathrm{~Hz}$ \\
Defrost heater & $115 \mathrm{~V}, 1$ phase, $60 \mathrm{~Hz}, 1.2 \mathrm{~kW}$, electrical heating element \\
Drain line heater & $115 \mathrm{~V}, 1$ phase, $60 \mathrm{~Hz}, 460 \mathrm{~W}$, electrical heating element \\
Door heater & $115 \mathrm{~V}, 1$ phase, $60 \mathrm{~Hz}, 115 \mathrm{~W}$, electrical heating element \\
Controller & KE-2 ADAPTIVE \\
\hline
\end{tabular}




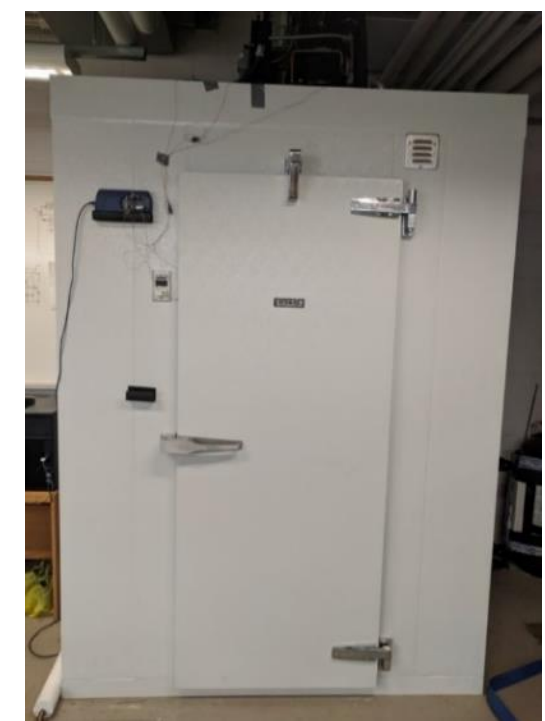

Figure 1: Photo of the tested walk-in freezer

The control unit (KE-2 Adaptive), shown in Figure 2, provides the user with two different options for defrost start. The first one is a "time schedule" such that the defrost start is based on a timer that can be adjusted as desired during the day. The second choice is an "on-demand" such that the defrost will start when the evaporator coil efficiency is less than $90 \%$. The coil efficiency is determined based on the temperature measurement of the leaving air from the coil and the coil surface temperature. When the KE2 Adaptive Control is powered initially, it develops an evaporator profile based on a series of system measurements. The controller completes a sequence of operational tests of the system, identifying a relationship between the coil temperature and the space temperature. The air sensor is located in the return air of the coil, while the coil sensor is located in the coldest point on the coil surface between the fins. For energy measurement, two Acuvim power meters were used (shown in Figure 3). The first one was used to measure the condensing unit power, and the second one was used to measure the evaporator coil fans and the defrost heater power. The measured data were recorded using a data logger software (Acuview).

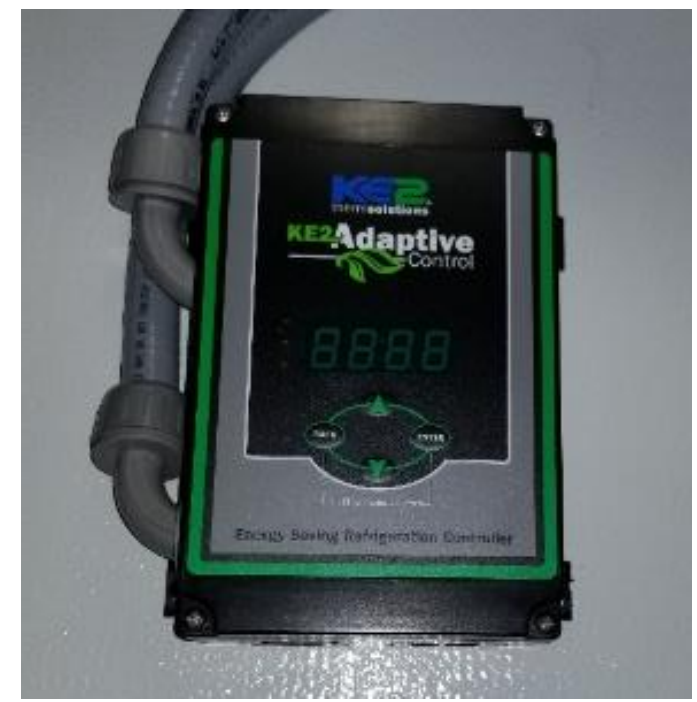

Figure 2: Control unit display panel. 


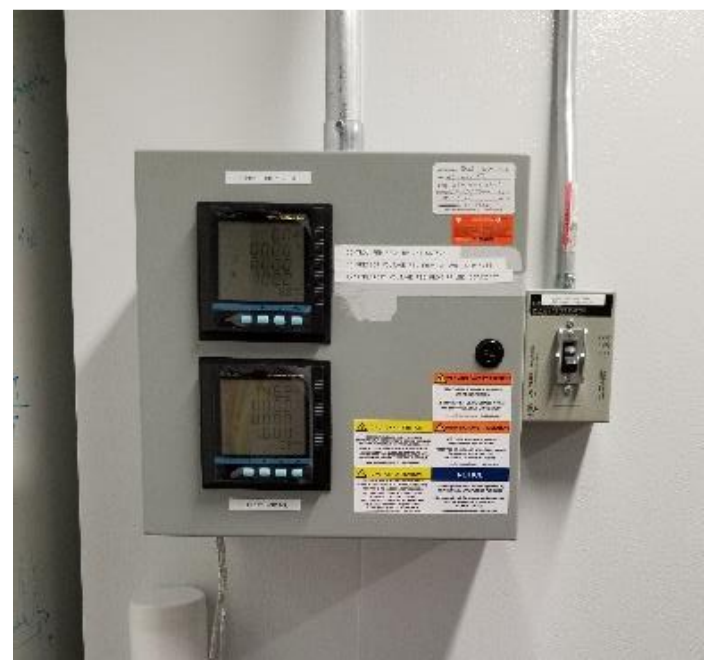

Figure 3: The two power meters used

\section{Methodology and Analysis}

The unit was adjusted to operate into two different modes, scheduled defrost and on-demand defrost. The test was a closed-door one where there is no thermal loading inside the freezer, just the heat gain from the ambient through the walls. Table 2 summarizes the experimental conditions for both settings.

Table 2: Test Conditions

\begin{tabular}{lll}
\hline Test Condition & On-Demand & Scheduled \\
\hline Test type & Closed-door & Closed-door \\
Setpoint temperature $\left(\mathrm{T}_{\text {set }}\right)$ & $-18{ }^{\circ} \mathrm{C}$ & $-18{ }^{\circ} \mathrm{C}$ \\
Defrost Initiation & When evaporator coil efficiency $<90 \%$. & Every 4 or 6 hours as per setting \\
\hline
\end{tabular}

The defrost-to-refrigeration ratio (DRR) is the total energy used to defrost the coil divided by the energy used in refrigeration between two successive defrost cycles as given by Eq. (1). Real-time power consumption as well as voltage, current, and power factor were recorded every twenty seconds. Hence, the average energy consumption during these intervals was calculated from multiplying the power value by the time interval to convert power $(\mathrm{kW})$ into energy $(\mathrm{kJ})$. Then those values during all measured time intervals were added together to obtain the total refrigeration and defrost energies. The refrigeration energy is considered the one consumed in operating the compressor and the fans (evaporator and condenser coils fans). The total energy used to defrost the coil includes the direct energy from the defrost heating element and the condensing unit energy consumed until the freezer reaches the setpoint after the defrost cycle ends. This is because the defrost causes an unwanted temperature increase that must be cooled down by the refrigeration system.

$$
D R R=\frac{\text { Defrost Energy }}{\text { Refrigeration Energy (between } 2 \text { successive defrost cycles })}
$$

An operational cost analysis was performed based on the data from 24 hours of operation to compare the scheduled defrost every 4 hours and 6 hours settings. Starting the reading from 7 AM, the energy data was recorded until the next day at $7 \mathrm{AM}$ to have 24 hours of operation. The cost was calculated based on three different energy price ratings charged by the Ontario Energy Board. The first price tag is during a weekday in the summer, and the second is during winter and the third 
charged price is at weekends. Figure 4 summarizes these categories. Assuming the consumption of the unit is consistent throughout the year, the annual operating cost was estimated.

\section{Ontario Electricity Time-of-use Price Periods}

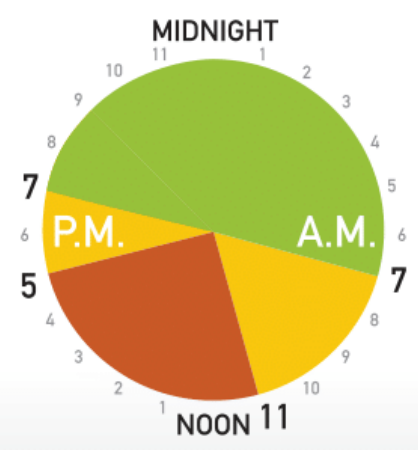

Summer

(May 1 - October 31) weekdays

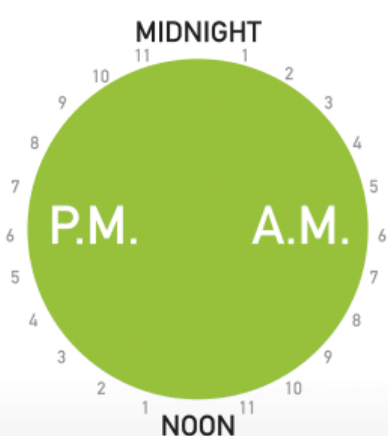

Weekends and Statutory Holidays

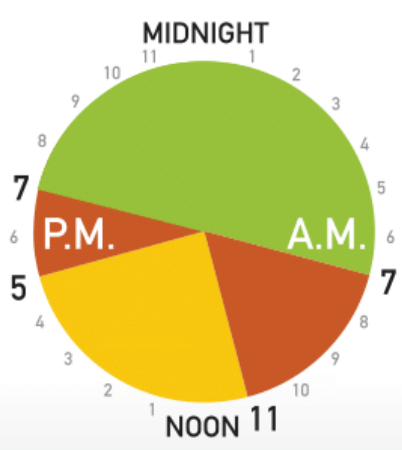

Winter

(November 1 - April 30) weekdays
Prices effective November 1, 2019

c/kWh Off-peak

14.4 Mid-peak

20.8

c/kWh On-peak

For more information visit OEB.ca

ONTARIO | COMMISSION \begin{tabular}{l|l} 
ENERGY & DEL'ENERGIE \\
BOARD & DEL'ONTARIO
\end{tabular}

Figure 4: Electricity tariff in Ontario during different seasons [7].

On-demand defrost mode was experimented under closed-door condition. The running test duration was for one week instead of one day. This is because of the unpredictable nature of the on-demand defrost mode where the number of the defrost cycles are dependant on the operating conditions of the unit. The only difference in cost estimation between the two modes is that instead of assuming one consistent day of operation, here the presumption is that the one-week operation is the same throughout the year.

\section{Results and Discussion}

Table 3 and Table 4 are summarizing the cost analysis during one day of operation and Table 5 is for one year. It can be noticed that there is a decrease in energy consumption when defrost is every six hours and that can be explained by the reduction in defrost energy. Moreover, there is also a significant reduction in DRR and it is because of the same reasoning. Figure 5 (a) and (b) illustrates the power consumption of the unit at the two settings defrost every 4 and 6 hours. 
(a)

(b)
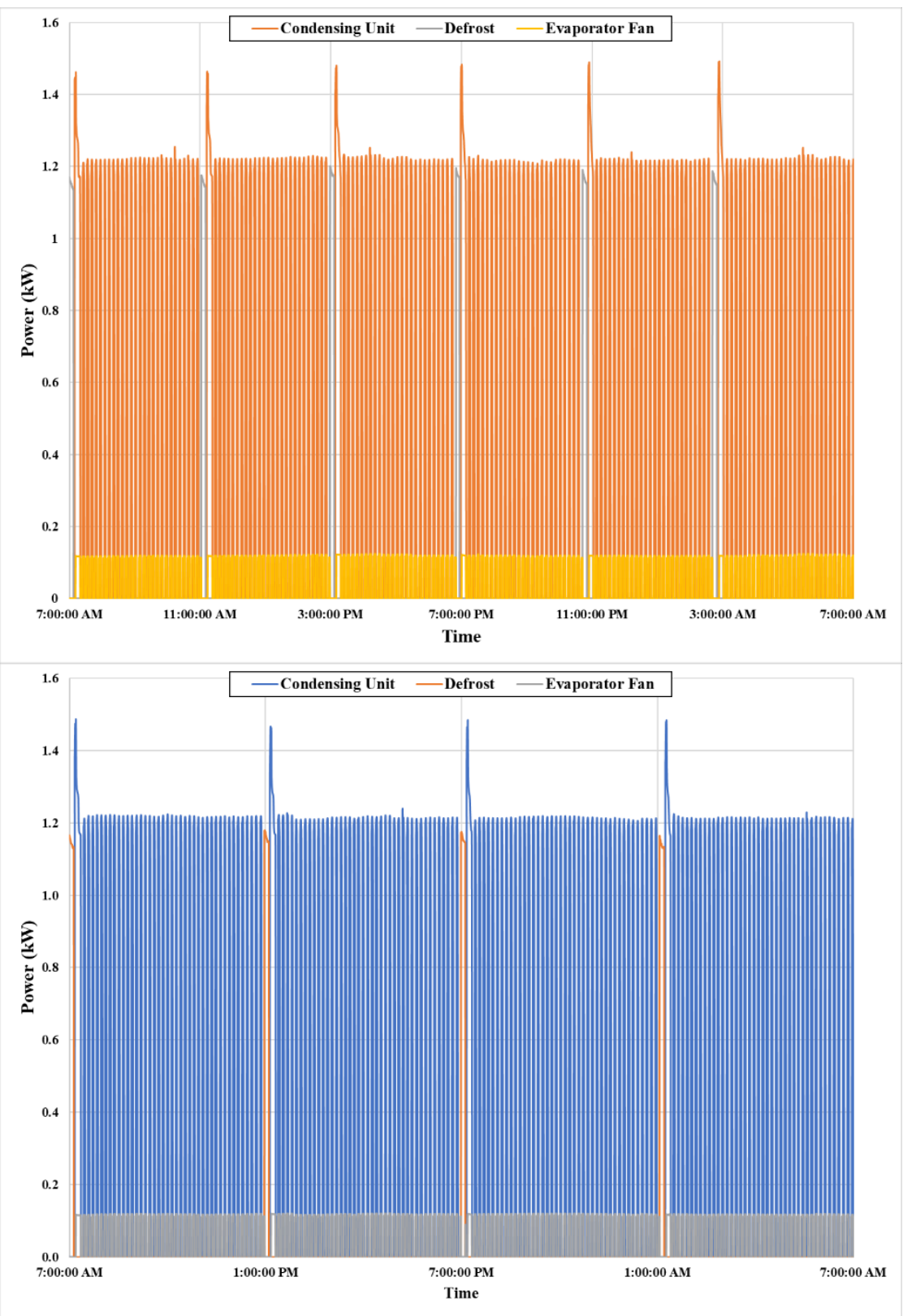

Figure 5: Power consumption (a) 4-hours defrost (b) 6-hours defrost

Table 3: One day of operation (defrost every 4 hours).

\begin{tabular}{llllll}
\hline & 7 AM - 11 AM & 11 AM - 5 PM & 5 PM - 7 PM & 7 PM - 7 AM & Entire Day \\
\hline Energy (kWh) & 1.922 & 2.971 & 0.881 & 5.488 & 11.263 \\
Summer weekday cost & $\$ 0.277$ & $\$ 0.618$ & $\$ 0.127$ & $\$ 0.554$ & $\$ 1.576$ \\
Winter weekday cost & $\$ 0.400$ & $\$ 0.428$ & $\$ 0.183$ & $\$ 0.554$ & $\$ 1.565$ \\
Weekend cost & $\$ 0.194$ & $\$ 0.300$ & $\$ 0.089$ & $\$ 0.554$ & $\$ 1.138$ \\
\hline
\end{tabular}


Table 4: One day of operation (defrost every 6 hours).

\begin{tabular}{llllll}
\hline & 7 AM - 11 AM & 11 AM - 5 PM & 5 PM - 7 PM & 7 PM - 7 AM & Entire Day \\
\hline Energy $(\mathrm{kWh})$ & 1.977 & 2.754 & 0.802 & 5.407 & 10.940 \\
Summer weekday cost & $\$ 0.285$ & $\$ 0.573$ & $\$ 0.115$ & $\$ 0.546$ & $\$ 1.519$ \\
Winter weekday cost & $\$ 0.411$ & $\$ 0.397$ & $\$ 0.167$ & $\$ 0.546$ & $\$ 1.521$ \\
Weekend cost & $\$ 0.200$ & $\$ 0.278$ & $\$ 0.081$ & $\$ 0.546$ & $\$ 1.105$ \\
\hline
\end{tabular}

The power consumption from the on-demand defrost mode is shown in Figure 6. In addition, the energy consumed is summarized in Table 6. The total energy consumed in one week is $65.685 \mathrm{kWh}$ and one-day consumption can be estimated to be 9.384 by dividing the one-week consumption by 7 assuming the same power consumed every day. This value indicates a reduction in the energy consumption; hence, the energy saving is $20.54 \%$ and $16.74 \%$ when using the adaptive control strategy instead of scheduled defrost every four and six hours, respectively. The reason behind that is also, due to the drop in the defrost energy which is reflected by less defrost initiations.

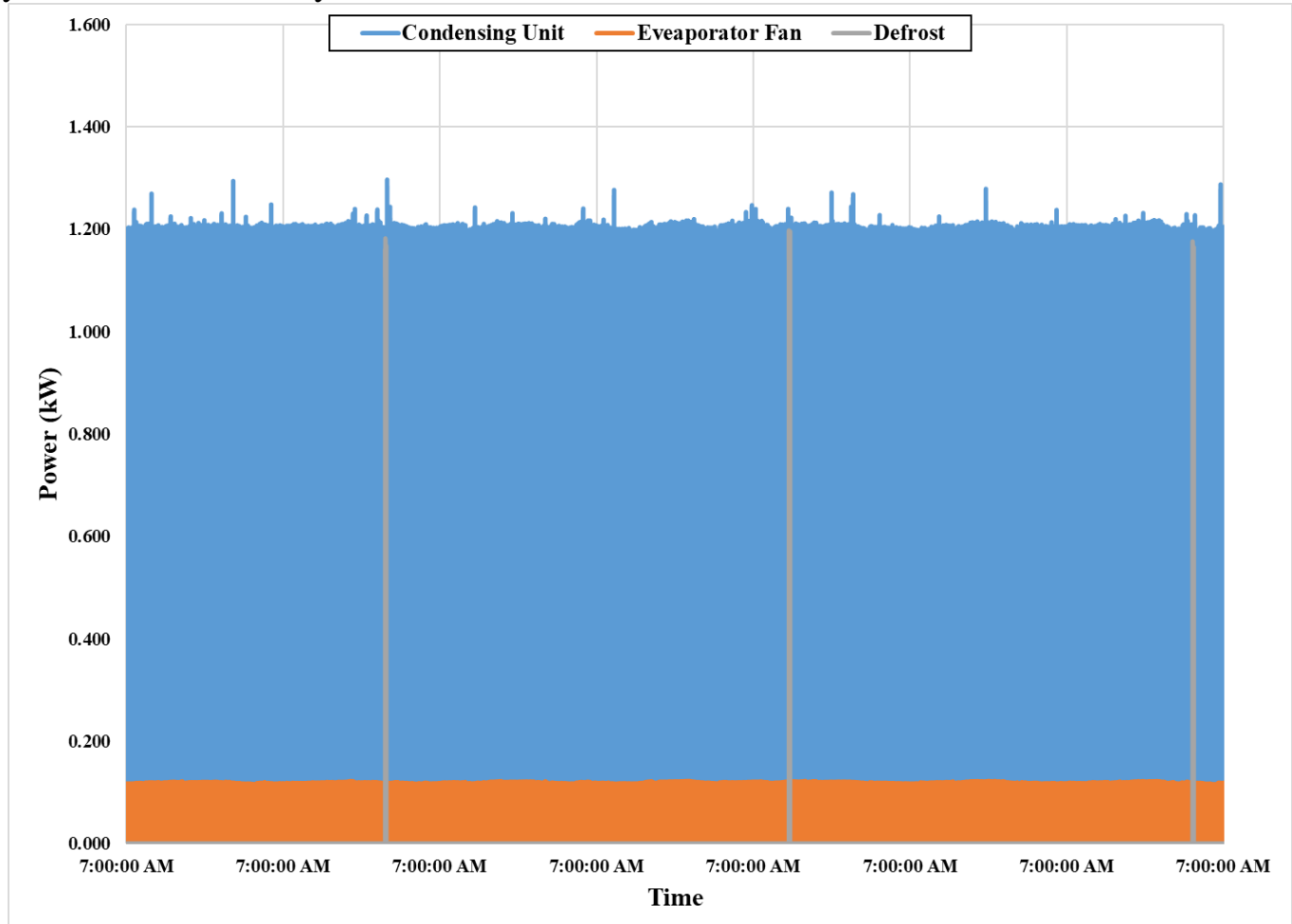

Figure 6: Power consumption (on-demand defrost mode) 
Table 6: The energy consumption of one week of operation (on-demand).

\begin{tabular}{lllllll}
\hline & & & & & \\
Day & $\begin{array}{l}\text { Energy } \\
7 \mathrm{AM}-11 \mathrm{AM} \\
(\mathrm{kWh})\end{array}$ & $\begin{array}{l}\text { Energy } \\
11 \mathrm{AM}-5 \mathrm{PM} \\
(\mathrm{kWh})\end{array}$ & $\begin{array}{l}\text { Energy } \\
5 \mathrm{PM}-7 \mathrm{PM} \\
(\mathrm{kWh})\end{array}$ & $\begin{array}{l}\text { Energy } \\
7 \mathrm{PM}-7 \mathrm{PM} \\
(\mathrm{kWh})\end{array}$ & $\begin{array}{l}\text { One-week } \\
\text { cost in } \\
\text { summer }\end{array}$ & $\begin{array}{l}\text { One-week cost in } \\
\text { Winter }\end{array}$ \\
\hline Monday & 1.600 & 2.281 & 0.783 & 4.673 & & \\
Tuesday & 1.578 & 2.384 & 0.752 & 4.891 & & $\$ 8.39$ \\
Wednesday & 1.527 & 2.325 & 0.727 & 4.586 & \\
Thursday & 1.600 & 2.327 & 0.785 & 4.568 & $\$ 8.40$ & \\
Friday & 1.572 & 2.512 & 0.758 & 4.526 & & \\
Saturday & 1.453 & 2.306 & 0.741 & 4.667 & & \\
Sunday & 1.582 & 2.375 & 0.787 & 5.020 & & \\
\hline
\end{tabular}

Table 7: Summary of the main findings

\begin{tabular}{llll}
\hline & On-demand & Every 4 hours & Every 6 hours \\
\hline Annual cost of operation & $\$ 437.87$ & $\$ 527.80$ & $\$ 511.16$ \\
Defrost-to-Refrigeration ratio (DRR) & $1.77 \%$ & $28.79 \%$ & $18.71 \%$ \\
Refrigeration cost & $\$ 465.63$ & $\$ 409.83$ & $\$ 430.58$ \\
defrost cost & $\$ 8.24$ & $\$ 117.97$ & $\$ 80.58$ \\
\hline
\end{tabular}

\section{Conclusion}

An experimental setup was used to investigate the energy used in defrost, alongside, cost analysis for one year of operation based on experimental data of real-time power consumption recorded and analyzed. The results show that the lower the number of defrost occurrences, the higher energy saving and cost reduction. In addition, the on-demand defrost mode showed better energy consumption savings compared to the scheduled mode. This indicates the importance of enhancing the defrost control strategy. The DRR values were found to be $29 \%, 19 \%$, and $2 \%$ for defrost every four hours, six hours, and on-demand defrost, respectively. Moreover, the energy-saving percentage was found to be $20.54 \%$ and $16.74 \%$ when using the adaptive control strategy instead of a timer scheduled to defrost every four and six hours, respectively. Lastly, the presented analysis did consider the impacts of the variation of the ambient conditions due to the seasonal effects on the energy consumption and the overall performance of the tested device, adding error to the cost analysis. Also, it is worth noting the infiltration and stored product loading effects are not taken into account.

\section{Acknowledgements}

The authors would like to thank Ontario Ministry of Agriculture Food and Rural (OMAFRA) and the University of Guelph in Canada, for funding the research reported in this paper, through program project \# 030371. 


\section{References}

[1] M. Amer and C. Wang, "Review of defrosting methods", Renewable and Sustainable Energy Reviews, vol. 73, pp. 5374, 2017.

[2] R. Mastrullo, A. Mauro, L. Menna, A. Palma and G. Vanoli, "Transient model of a vertical freezer with door openings and defrost effects", Applied Energy, vol. 121, pp. 38-50, 2014.

[3] B. Borges, C. Hermes, J. Gonçalves and C. Melo, "Transient simulation of household refrigerators: A semi-empirical quasi-steady approach", Applied Energy, vol. 88, no. 3, pp. 748-754, 2011. Available: 10.1016/j.apenergy.2010.09.019.

[4] B. Borges, C. Melo, and C. Hermes, "Prediction of Evaporator Frosting in Household Refrigerators Subjected to Periodic Door Opening". International Refrigeration and Air Conditioning Conference. West Lafayette, IN, United States, 14-17 July, 2014.

[5] X. Yuan, and D. L. Neal, "Development of a Transient Simulation Model of a Freezer Part I: Model Development". International Refrigeration and Air Conditioning Conference. West Lafayette, IN, United States, 1994.

[6] A. Behfar, and D. P. Yuill, "Numerical Simulation of Fault Impacts for Commercial Walk-in Freezers". International Refrigeration and Air Conditioning Conference, West Lafayette, IN, United States, 9-12 July, 2018.

[7] Ontario Energy Board, "Ontario Wholesale Electricity Market Price Forecast Report" (2019), Available at https://www.oeb.ca/sites/default/files/rpp-wholesale-electricity-market-price-forecast-20191022.pdf 